\title{
ZOOMLENS GRAPHIC FORM OF DATA PRESENTATION ON A WEB MAP, COMPARISON OF CHOSEN TOOL AND USAGE EXAMPLES
}

\author{
Karol Krol \\ University of Agriculture in Krakow, Poland \\ k.krol@onet.com.pl
}

\begin{abstract}
There are more and more users of the Internet, who actively make use of public techniques and programmatic tools. They often form social groups concentrated around various IT projects on a global scale. They just as often work individually creating different applications and providing them free of charge. The aim of the paper is a comparative analysis of chosen components, which extend functionality of websites by the possibility to present data concentrated in the small area of a web map, the visibility of which depends on a degree of approximation of a map view. Chosen project tools that base on raster and vector maps were tested. In conclusion it was proved that the tested tools can be applied in projects from the trend called Volunteered Geographic Information (VGI) and in view of the attractive graphic form can also be used in commercial websites, for example, to present offered assortment.
\end{abstract}

Keywords: web engineering, geo-visualization, interactive zoomlens, data visualization, ad-hoc maps.

\section{Introduction}

In the last decade, web maps became a necessary component of web sites and applications. This is among others because of the big technological progress in the range of methods of providing geographic data and also holding huge collections of data of such type by companies and public institutions. Popularity of positional and navigational services that act as touristic or car web maps or city plans increases. In turn, public administration units of different level provide geo-information portals that present considerable geodetic and cartographic data sets. Thanks to internet services, where the key component is geographic location, users got a possibility to identify objects in space easily. Technologies of publication of geo-data, which are often provided with the extensive documentation and in the form that allows their common usage, gave users opportunity to choose data and the way of their visualization and also to place in services new data, which can, in turn, become available for other users - now web applications that provide advanced geo-visualization simplify editing maps for personal use increasing efficiency of work with geographic information.

From the perspective of engineering matters, web maps are most often "called" in a browser window through: a hyperlink to a defined map (link), map's presentation in a window as "a floating frame" (HTML iframe) or direct implementation of a map by means of various programmatic libraries. Displaying a map using the web resource address parameterisation method after writing down an URL (uniform resource locator) address in a browser address bar is also possible.

Occurrence of application programming interfaces (API) as procedures, protocols and tools to build web applications contributed to creating numerous and better services of mashup type as well as hybrid applications [1]. They join the chosen topic contents with the map base provided by geo-data providers. API allows to program map services, which can among others be a component of a website [2-4].

\section{Purpose and goals of the research}

Publishing information and diverse data including environmental ones became possible without knowledge of advanced programmatic techniques and only by means of content management systems (CMS), which use graphical user interface (GUI) and allow to publish data in an automated way. Moreover, a number of components, which extend websites' functionality, increased significantly in recent years. They take different forms according to their tasks as well as the software functionality of which they extend.

Crucial advantage of components is their modularity - they can be used in several projects at the same time and can also be turned on and off on the user's demand - their construction is compact, which allows to implement them in a relatively simple way (they are commonly called plugs or "a packet of scripts"). Moreover, in case of software of Open Source type they are created and improved by users' community. 
In a wide range of various components, which extend functionalities of websites and applications, these responsible for presentation of data, which have spatial reference, can be found. The aim of the paper is the comparative analysis of chosen components that extend functionality of websites by possibilities to present data concentrated in a small area on a web map, visibility of which depends on the degree of approximation of the map's view. The aim of the work is also to measure the performance of the tested applications.

\section{Materials and methods}

A "zoomlens" or magnifying glass (an interactive lens) is a specific tool, which can be qualified to these from the range of navigation support. Its basic function is to present areas of a graphic (vector or raster) file with great concentration of objects, which due to the level of map's generalization are hidden, cumulated, presented as one object or poorly visible.

Fundamental project assumption was to create model data visualization on a web map - a raster or vector one - on which cumulated (concentrated) in the slight area points of interest (POI) were applied and visibility of which depends on the level of approximation of a map's view. It was further assumed that visualization should take the form of a hypertext document of plug-in type, i.e. a so called plug, which extends its functionality and the size of a window should not exceed 1000x400px (width and height attributes of a window of map's presentation). It was also assumed that the task of a component created in such a way should enhance the text information with spatial data, which would not only play the informational role, but also make data transfer more attractive both in graphic (visual) aspect and through interactivity and usability.

To create components in accepted specification, chosen tools provided within the licenses that do not need to be paid for using them even in commercial projects were used (Table 1). During project works, explorative tests of "ad-hoc" type were performed on the basis of functionality and project possibilities from the point of view of a common user using self-assessment technique and registering observations made in the process of project works [5-6].

Characteristics of tested project tools

Table 1

\begin{tabular}{|c|c|c|c|}
\hline Specification & Visualization: GeoChart & jQuery elevateZoom & ImageLens \\
\hline Project techniques & $\begin{array}{l}\text { SVG, VML, Visualization } \\
\text { API (magnifying glass), } \\
\text { HTML, CSS }\end{array}$ & $\begin{array}{l}\text { JavaScript, jQuery, } \\
\text { HTML, CSS }\end{array}$ & $\begin{array}{l}\text { JavaScript, jQuery, } \\
\text { HTML, CSS }\end{array}$ \\
\hline Form of a map & Vector & Raster & Raster \\
\hline $\begin{array}{l}\text { Type of a lens, form of } \\
\text { approximation of } \\
\text { map's view }\end{array}$ & $\begin{array}{c}\text { Magnifying glass, round } \\
\text { lens }\end{array}$ & $\begin{array}{c}\text { Window zoom, lens zoom } \\
\text { and inner zoom, polygonal } \\
\text { lens }\end{array}$ & $\begin{array}{l}\text { Magnifying glass, } \\
\text { round lens }\end{array}$ \\
\hline License & $\begin{array}{l}\text { Google Maps/Google Earth } \\
\text { APIs Terms of Service }\end{array}$ & $\begin{array}{l}\text { Dual licensed under both } \\
\text { the MIT and GPL licenses. }\end{array}$ & CC BY 3.0 \\
\hline Specification & jfMagnify & MagnifierRentgen & Easy Image Zoom \\
\hline Project techniques & $\begin{array}{c}\text { JavaScript, jQuery, HTML, } \\
\text { CSS }\end{array}$ & $\begin{array}{c}\text { JavaScript, jQuery, } \\
\text { HTML, CSS }\end{array}$ & $\begin{array}{c}\text { JavaScript, jQuery, } \\
\text { HTML, CSS }\end{array}$ \\
\hline Form of a map & Raster & Raster & Raster \\
\hline $\begin{array}{l}\text { Type of a lens, form of } \\
\text { approximation of } \\
\text { map's view }\end{array}$ & $\begin{array}{c}\text { Magnifying glass, round } \\
\text { lens }\end{array}$ & $\begin{array}{c}\text { Magnifying glass, round } \\
\text { lens }\end{array}$ & $\begin{array}{l}\text { Panorama, zoom in } \\
\text { the map display } \\
\text { window }\end{array}$ \\
\hline License & „Use as you like” & MIT license & MIT license \\
\hline Specification & Cropping & Cropit & Magnificent \\
\hline Project techniques & $\begin{array}{c}\text { JavaScript, jQuery, HTML, } \\
\text { CSS }\end{array}$ & $\begin{array}{c}\text { JavaScript, jQuery, } \\
\text { HTML, CSS }\end{array}$ & $\begin{array}{c}\text { JavaScript, jQuery, } \\
\text { HTML, CSS }\end{array}$ \\
\hline Form of a map & Raster & Raster & Raster \\
\hline $\begin{array}{l}\text { Type of a lens, form of } \\
\text { approximation of } \\
\text { map's view }\end{array}$ & $\begin{array}{c}\text { Zoom in the map display } \\
\text { window }\end{array}$ & $\begin{array}{l}\text { Zoom in the map display } \\
\text { window }\end{array}$ & $\begin{array}{l}\text { Zoom in the map } \\
\text { display window }\end{array}$ \\
\hline License & MIT License & MIT License & MIT license \\
\hline
\end{tabular}


Explorative (exploratory) tests are ones of less formal methods of testing software. They are usually performed without earlier planned test cases, however, with a set target and of preliminary character [7]. Improvisation often accompanies them and that is why they can be difficult to reconstruct. Explorative tests usually precede the basic ones, they support their planning or because of resources or time limits they can replace them completely.

Website performance is often equated with the speed of loading the site in the browser window. The website's performance is largely due to the design solutions adopted, including the techniques and components that had been used to create it [16]. Performance tests were performed in an informal manner, using selected online applications (Table 2). The achieved score was subsequently normalised using the zero unitarisation method.

Table 2

\section{Online applications used in performance testing}

\begin{tabular}{|c|c|c|}
\hline Analysis tool & Website & Measurement unit \\
\hline GTmetrix & gtmetrix.com & PageSpeed Score, YSlow \\
\hline Pingdom Website Speed Test & tools.pingdom.com & Performance grade \\
\hline Dareboost: Website Speed Test (DaM) & dareboost.com & Speed Index \\
\hline
\end{tabular}

The GTmetrix application measures the website's performance, its loading time in the browser window, and the sizes of its components. The result of the performance measurement is presented using the PageSpeed Score and YSlow indices. The YSlow attribute is expressed with a synthetic point score, ranging between 0 and 100 points. The Pingdom application provides information about the website's performance, its loading time, the number of requests, and the sizes of its components. Dareboost provides a module for testing the applications in the mobile and desktop mode. The result of the measurements is presented in the form of a synthetic point score and the Speed Index. The faster the rendering, the lower the index value, with Google recommending that it does not exceed 1000 units [16].

The initial set of variables was standardized using the zero unitarisation method, whereas transformation (1) was applied for stimulant variables (S), and transformation (2), for deterrent variables (destimulants, D). Zero unitarisation is a method of normalising diagnostic features, and is characterised by a constant reference point. Normalisation is an operation aimed at the adaptation of diagnostic variables to the role of partial criteria in the process of complex phenomenon assessment [17].

$$
\begin{aligned}
& x_{i j}^{\prime}=\frac{x_{i j}-\min _{i}\left\{x_{i j}\right\}}{\max _{i}\left\{x_{i j}\right\}-\min _{i}\left\{x_{i j}\right\}}, \\
& x_{i j}^{\prime}=\frac{\max _{i}\left\{x_{i j}\right\}-x_{i j}}{\max _{i}\left\{x_{i j}\right\}-\min _{i}\left\{x_{i j}\right\}} .
\end{aligned}
$$

Next, the value of the meta-variable (F-Score) was determined by adding up the values of all standardized diagnostic features. Therefore, the normalisation of features enables comparative testing on objects (complex phenomena) described using many variables.

\section{Results and discussion}

Functionality of the tested tools basically limits to presentation of approximated map's fragment in a lens's window, although in case of Visualization: GeoChart, values, which are dynamically presented in a pop-up type window as well as in a map's key, can be assigned to punctual objects (Fig. 1a). There is lack of such functionality in case of the other tools. Visualizations created by means of Visualization: GeoChart can mainly expand a text message. Moreover, due to their attractive graphic form they can focus users' attention.

In case of jQuery elevateZoom and ImageLens components there is lack of "classic" (numerical, tabular) data source. ElevateZoom and ImageLens are based on raster grounds. In such a case the only information for the receiver of data transfer goes from the range of data presented at the raster map (Fig. 1b). The situation is different in case of Visualization: GeoChart. Components prepared in such a way are based on vector graphics. Every object that is placed on a map, for example, on the basis of 
geographic coordinates or region codes can be accompanied by any information, both text and numerical ones. They are placed in a data table (data array).

JfMagnify is an interesting tool created and made available free of charge by Fahnestock [8] based on free usage rule "use as you like". Prepared on the basis of jQuery library, the tool stands out from many others with the form of raster's presentation. Here, the commonly used lens's window was supplemented with buttons of zooming a map in and out located in the immediate vicinity of the lens (Fig. 2). In the other version, the tool presents an extended view of the map in a separate window placed in any area of map's presentation. These apparently slight extensions cause that a standard lens becomes ever more interactive and can be more attractive for a user in the reception.

(a)

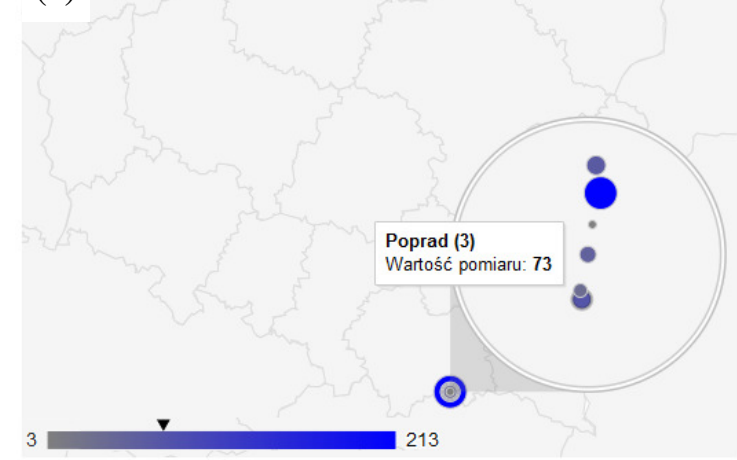

(b)

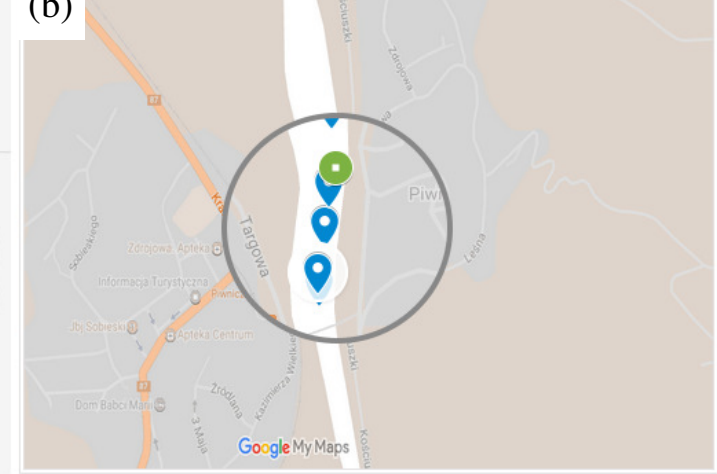

Fig. 1. From left: fragment of web map made by means of Visualization API - measuring points on the Poprad river, screenshot (a); Google hydrographic map - presentation of measuring points in the lens's window made by means of jQuery elevateZoom (b), screenshot. Source: own elaboration

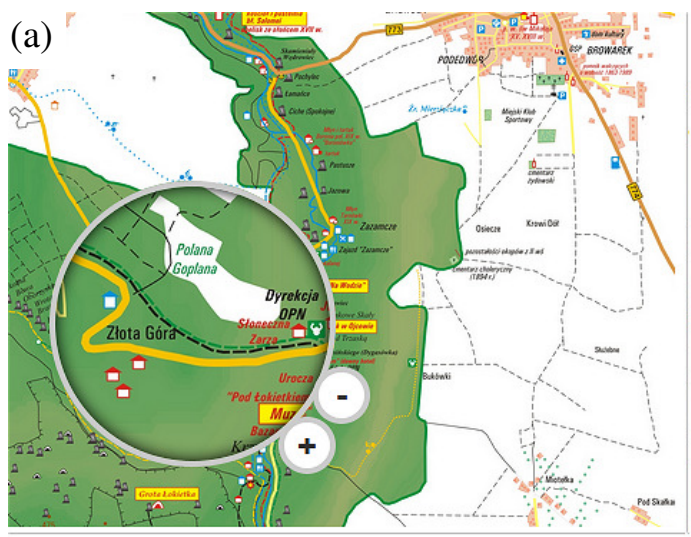

Fig. 2. From left: fragment of touristic map of Ojców National Park presented in window of interactive lens (jfMagnify) - extended by navigation buttons (a) and presented in an independent window (b), screenshot. Source: own elaboration

Another interesting solution is a script, which is also prepared on the basis of jQuery JavaScript and meaningfully called MagnifierRentgen (jQuery MagnigierRentgen Plugin) [9]. While the other tools use one raster file, which is scaled straight in a browser window, MagnifierRentgen can present in a lens's window any other raster file. This may have considerable significance for component efficiency because primarily in that case there can be downloaded a map, which can be prepared in a high extent of generalisation, i.e. with less detail that is less size in pixels, which, in turn, results in less number of data transferred by the Web. Some sort for round lenses are these, which realize approximation of a map's view in a window taking the shape of a polygon - adjacent or directly in the area of map's presentation. Easy Image Zoom jQuery Plugin can serve as an example [10]. 
Apart from components, where functionality of map's view approximation is realized in a window of an interactive lens, there are many others available in the Web, which use for that purpose a graphic interface GUI. One of them is Cropit (customizable crop and zoom jQuery plugin) [11], where the map's view approximation is realized by means of so called interactive slider bar (Fig. 3a). Scripts "Cropping jQuery plugin" (Fig. 3b) [12] or "Magnificent" [13], which can be configured in many ways, can be an alternative (solutions based on an alternative menu usually provide more possibilities of configuration of map's view presentation).
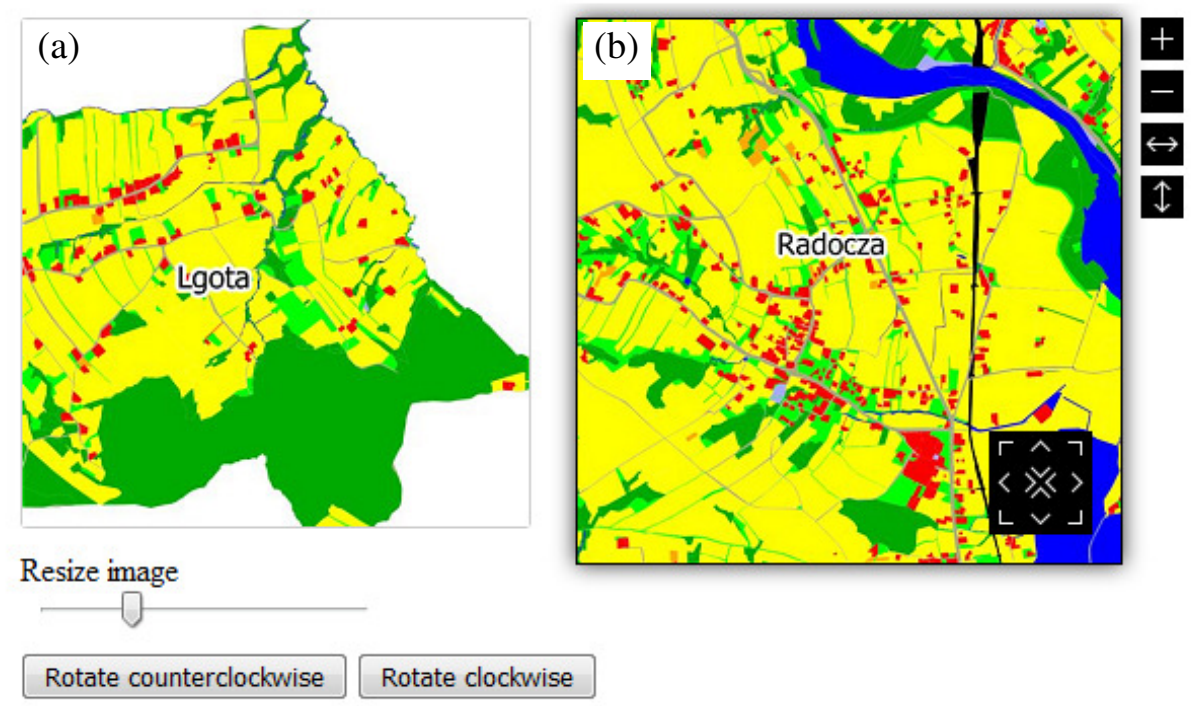

Export

Fig. 3. Map of spatial diversity of farmlands in Tomice commune which can be browsed by means of navigation buttons - (a) Cropit script, (b) Cropping script, screenshot. Source: own elaboration

Map's view approximation in components like "an interactive lens" takes place in a window - a round or polygonal one, shaded or not, with a diverse frame within which picture's approximation is presented. Tools of such type are usually performed on the basis of jQuery JavaScript library. Their usage needs previous preparing of data in a raster form - a map, an infographics etc. The components, which generate approximation of a picture in an adjacent window or directly in a window of map's presentation, can be included in the set of such functioning components. It takes place in the whole range of a window and not in its separated area (fragment) as it happens in case of interactive lenses. In these tools, zooming in or out of a map's view by means of computer mouse's buttons can be configured. Moreover, diverse activities on a map, including view's approximation, map's browsing and turning can be realized through a graphic users interface (GUI), which is often composed of an interactive "slider" or classic toolbars.

Every tested tool allows to create map components, but in a restricted range. The area of a map presented by them is limited - in case of Visualization: GeoChart - to map bases defined by a service provider (areas divided into countries, regions and metropolitan areas according to the norms: ISO3166-1 alpha-2, ISO-3166-2, respectively, and three-digit metro codes - codes available on a website of a service provider are at the disposal of the user). In case of the remaining ones - to a raster size. Moreover, the tested project techniques, despite they can be treated as a group of techniques that enable dynamic change of a hypertext document's content, look or acting (Dynamic HyperText Markup Language, DHTML), allow to prepare components actually static (Table 3). It is reflected in lack of possibility to catch, drag (browse, move) the map's area, which is by way of advance defined by the extension's author. It results somewhat from the character of the tools themselves. First and foremost, they play presentation and illustrative functions. As far as Visualization: GeoChart tool is predisposed to visualizing various data on maps of continents, countries and chosen regions, in other cases any raster file can be treated with the effect of approximation, which makes the tools universal. However, the quality of approximation, i.e. the picture presented in within the lens depends directly on 
the raster's quality. The bigger its resolution, the more effective approximation will be. It is connected with the component's efficiency and the number of data bytes sent in the Web, which in this case can slow down the whole website.

Table 3

Chosen functionalities of tested project tools

\begin{tabular}{|c|c|c|c|}
\hline Functionality range & Visualization: GeoChart & jQuery elevateZoom & ImageLens \\
\hline Interactive zoomlens & + & + & + \\
\hline $\begin{array}{c}\text { General approximation } \\
\text { of a map's view }\end{array}$ & - & + & + \\
\hline Map legend & + & $-1+$ & $-1+$ \\
\hline $\begin{array}{l}\text { Pop-up type } \\
\text { information }\end{array}$ & + & - & - \\
\hline Map legend form & Dynamic & Only as raster's fragment & Only as raster's fragment \\
\hline Map area & $\begin{array}{l}\text { Limited to chosen } \\
\text { presentation form }\end{array}$ & Limited by raster's size & Limited by raster's size \\
\hline $\begin{array}{c}\text { Additional } \\
\text { functionalities }\end{array}$ & $\begin{array}{l}\text { Interactive map legend } \\
\text { and information in pop-up } \\
\text { window }\end{array}$ & $\begin{array}{l}\text { Full service with a mouse cursor, } \\
\text { presentation of a map in a lens } \\
\text { and in a parallel window }\end{array}$ & $\begin{array}{l}\text { Possibility to define the } \\
\text { other main map than the one } \\
\text { presented in the lens }\end{array}$ \\
\hline Functionality range & jfMagnify & MagnifierRentgen & Easy Image Zoom \\
\hline Interactive zoomlens & + & + & + \\
\hline $\begin{array}{c}\text { General approximation } \\
\text { of a map's view }\end{array}$ & + & + & + \\
\hline Map legend & $-1+$ & $-1+$ & $-1+$ \\
\hline $\begin{array}{l}\text { Pop-up type } \\
\text { information }\end{array}$ & + & - & - \\
\hline Map legend form & Only as raster's fragment & Only as raster's fragment & Only as raster's fragment \\
\hline Map area & Limited by raster's size & Limited by raster's size & Limited by raster's size \\
\hline $\begin{array}{c}\text { Additional } \\
\text { functionalities }\end{array}$ & $\begin{array}{l}\text { Possibility to extend lens } \\
\text { by buttons of map's view } \\
\text { approximation }\end{array}$ & $\begin{array}{l}\text { Possibility to define the other } \\
\text { main map than the one presented } \\
\text { in the lens }\end{array}$ & $\begin{array}{l}\text { Possibility to switch off the } \\
\text { lens effect }\end{array}$ \\
\hline Functionality range & Cropping & $\begin{array}{c}\text { Cropit } \\
\end{array}$ & Magnificent \\
\hline Interactive zoomlens & - & - & $-1+$ \\
\hline $\begin{array}{c}\text { General approximation } \\
\text { of a map's view }\end{array}$ & + & + & + \\
\hline Map legend & $-1+$ & $-1+$ & $-1+$ \\
\hline $\begin{array}{l}\text { Pop-up type } \\
\text { information }\end{array}$ & - & - & - \\
\hline Map legend form & Only as raster's fragment & Only as raster's fragment & Only as raster's fragment \\
\hline Map area & Limited by raster's size & Limited by raster's size & Limited by raster's size \\
\hline $\begin{array}{c}\text { Additional } \\
\text { functionalities }\end{array}$ & $\begin{array}{l}\text { Full map service with a } \\
\text { mouse or by means of } \\
\text { buttons in menu }\end{array}$ & $\begin{array}{l}\text { Possibility to load automatically } \\
\text { any raster map }\end{array}$ & $\begin{array}{l}\text { Big number of variants of } \\
\text { map's view approximation }\end{array}$ \\
\hline
\end{tabular}

The performed analysis can raise a question where in practice the described project tools can be applied and whether they can be used to create components of formal map elaborations and environmental data presentations. Whereas maps presented in websites usually have explanatory character and cannot be treated as official documents, their form of presentation can be theoretically different. However, it depends on the presented content's kind and range. The more expanded and "official" the maps are, the more advanced technically their form is. It should also be a part of conception of spatial information infrastructure. So, the discussed tools can be applied in projects from the trend geographic information created by the users' community (Volunteered Geographic Information, VGI), created by "users - creators, users - producers" (producer) [14]. They represent the community of active volunteers, which compose a group of authors of contents available in the Internet (produsage, user-generated content) [15]. The presented tools can be also used to create components that form extension of websites, which serve commercial activities, for example, increasing attractiveness of offered products presentation.

The selected diagnostic variables $\left\{X_{1}, \ldots, X_{4}\right\}$ were subjected to normalisation process by use of the zero unitarisation method. The variables $\left\{X_{1}, X_{2}, X_{3}\right\}$ were normalised by the use of the model (1), 
while the variable $\left\{X_{4}\right\}$ was transformed by the use of the formula (2). Web components ranking considering the value of performance tests is demonstrated in Table 4.

Table 4

Measurement results for selected performance indices

\begin{tabular}{|l|c|c|c|c|c|}
\hline Analysis tool & $\begin{array}{c}\text { GTmetrix } \\
\text { PageSpeed } \\
\text { Score }\end{array}$ & $\begin{array}{c}\text { GTmetrix } \\
\text { YSlow }\end{array}$ & $\begin{array}{c}\text { Pingdom } \\
\text { Performance } \\
\text { grade }\end{array}$ & $\begin{array}{c}\text { Dareboost } \\
\text { Speed Index }\end{array}$ & \multirow{2}{*}{ F-Score } \\
\hline Type of the variable & $\boldsymbol{S}\left(\boldsymbol{X}_{\mathbf{1}}\right)$ & $\boldsymbol{S}\left(\boldsymbol{X}_{\mathbf{2}}\right)$ & $\boldsymbol{S}\left(\boldsymbol{X}_{\mathbf{3}}\right)$ & $\boldsymbol{D}\left(\boldsymbol{X}_{\mathbf{4}}\right)$ & \\
\hline Cropit & 98 & 94 & 98 & 634 & 4.000 \\
\hline ImageLens & 94 & 92 & 96 & 767 & 3.476 \\
\hline jQuery elevateZoom & 93 & 91 & 94 & 955 & 2.997 \\
\hline Easy Image Zoom & 91 & 90 & 92 & 967 & 2.716 \\
\hline Magnificent & 89 & 89 & 91 & 942 & 2.563 \\
\hline MagnifierRentgen & 90 & 85 & 90 & 938 & 2.188 \\
\hline Cropping & 87 & 81 & 93 & 864 & 2.185 \\
\hline jfMagnify & 9 & 91 & 96 & 1472 & 1.603 \\
\hline Visualization: GeoChart & 98 & 86 & 86 & 1400 & 1.471 \\
\hline
\end{tabular}

The performance measurements made with the GTmetrix and Pingdom tools give similar results. The values of PageSpeed Score and Pingdom Performance grade are slightly lower than of the YSlow indicator. This is due to the differences in the way the indicators are calculated. Only in two cases the Dareboost Speed Index exceeded the recommended 1.000 units. This occurred in the GeoChart Visualization component, which uses external Google resources, and the jfMagnify component, which comprises a large-size grid. Noticeable is the value of the PageSpeed Score GTmetrix equal to 9 units and obtained in the jfMagnify measurement. This may be due to the use of a large-size raster as well. Similar conclusions have been drawn in other studies [16].

\section{Conclusions}

The research suggests that the following factors could have the greatest impact on the performance of components: (1) the size of the raster map (in components that use the raster); and (2) the number of components retrieved from external sources, e.g. jQuery library. It is advisable to modify the components in such a way so that they are consolidated within one data server.

Using the chosen project techniques and tools provided free of charge to create website components that enable the map's view approximation was presented in the paper. The described tools were not created from the base, but only modified (personalised) according to the accepted project specification. Such procedure can be observed more and more frequently in projects created in "produser", "produsage" trends. It results among others from progressive digitization, availability of computer techniques and tools, and also databases. It also results from growing awareness of new technologies - knowledge of analytic techniques and interdisciplinary skills of their users as well as the increasing role of aesthetics and expectations of users in regard to transfer attractiveness. Functionality of the tested tools depends to a large extent on the user's programmatic knowledge. The bigger it is, to a greater extent they are able to adapt the tool to their own needs.

The analysis of various scripts - that base on static maps and are usually created by help of jQuery JavaScript library, which allowed to perform a component according to accepted project assumption - enabled to divide them into three basic groups: interactive lenses (round or in the form of a polygon); scripts that realize picture's approximation in an adjacent window or directly in the area of the map's presentation (usually through orders issued directly with the mouse buttons) and scripts, where map's view approximation is realized through navigation menu (often in connection with possibility to issue orders with the mouse buttons).

The tested project tools that realize map's view approximation and performed by means of jQuery JavaScript library cannot for a common user differ basically from each other. Depending on the project objectives specific applications can find classic or "complex" solutions, for example, as in the case of "jfMagnify" tool. Tools that perform map's view approximation by means of GUI graphic interface differ slightly more from each other. As an interactive lens usually takes a round or 
polygonal shape, insofar graphical layout and functionality range of the map's navigation menu can be very different.

\section{Acknowledgments}

This research was financed by the Ministry of Science and Higher Education of the Republic of Poland, No. 2309.

\section{References}

[1] Yu J., Benatallah B., Casati F., Daniel F. Understanding mashup development. IEEE Internet Computing, Vol. 12(5), 2008, pp. 44-52. doi: 10.1109/MIC.2008.114

[2] Bowie G.D., Millward A.A., Bhagat N.N. Interactive mapping of urban tree benefits using Google Fusion Tables and API technologies. Urban Forestry \& Urban Greening, Vol. 13(4), 2014, pp. 742-755. doi: 10.1016/j.ufug.2014.06.002

[3] Lee M.G., Yu K.M., Chien S. T. Visualize Field Data in Fusion Tables-Take Chung Hua University Plant Map as Example. In Ubi-Media Computing and Workshops (UMEDIA), 7th International Conference, 2014, pp. 261-265, doi: 10.1109/U-MEDIA

[4] Nair L., Shetty S., Shetty S. Interactive visual analytics on Big Data: Tableau vs D3. js. Journal of e-Learning and Knowledge Society, Vol. 12(4), 2016, pp. 139-150.

[5] Afzal W., Torkar R., Feldt R. A systematic review of search-based testing for non-functional system properties. Information and Software Technology, Vol. 51(6), 2009, pp. 957-976.

[6] Chhabra M.N. Introduction To Adhoc Testing. International Journal of Scientific and Technology Research, Vol. 1(7), 2012, pp. 66-67.

[7] Itkonen J., Mäntylä M.V. Are test cases needed? Replicated comparison between exploratory and test-case-based software testing. Empirical Software Engineering, Vol. 19(2), 2014, pp. 303-342.

[8] Fahnestock J. jQuery plugin that creates a magnify glass effect. [online] [11.01.2019]. Available at: https://github.com/fonstok/jfMagnify

[9] Agragregra. WebDesign Master. jQuery MagnigierRentgen Plugin. [online] [11.01.2019]. Available at: http://agragregra.github.io/demos/MagnifierRentgen/

[10] Grakalic A. Easy Image Zoom jQuery Plugin (Css Globe, Easy front-end framework). [online] [11.01.2019]. Available at: http://cssglobe.com/lab/easyzoom/easyzoom.html

[11] Cheng S.A customizable crop and zoom jQuery plugin (scottcheng/cropit). [online] [03.01.2019]. Available at: https://github.com/scottcheng/cropit

[12] Banaszkiewicz A. Another cropping jQuery plugin (requtize/cropimg). [online] [04.01.2019]. Available at: https://github.com/requtize/cropimg

[13] Johnson A.D. Magnificent.js. Zoom responsively. A jQuery plugin for responsive zoom of images \& more!. [online] [03.01.2019]. Available at: https://github.com/adjohnson916/magnificent.js

[14] Haklay M. How good is volunteered geographical information? A comparative study of OpenStreetMaps and Ordnance Survey dataset. Environmentanal and Planing B: Planning and Design, Vol. 37(4), 2010, pp. 682-703.

[15] Coleman D., Georgiadou Y., Labonte J. Volunteered geographic information: The nature and motivation of produsers. IJSDIR, Vol. 4(1), 2009, pp. 332-358.

[16] Król K. Performance threshold of the interactive raster map presentation - as illustrated with the example of the jQuery Java Script component. Geographic Information Systems Conference and Exhibition GIS ODYSSEY, 2018, pp. 321-327.

[17] Kukuła K., Bogocz D. Zero unitarization method and its application in ranking research in agriculture. Economic and Regional Studies, Vol. 7(3), 2014, pp. 5-13. 